\title{
Clinical Profile and Validity of PRISM III among Children Admitted in a PICU Over One Year
}

\author{
A K Simalti \\ Dept of pediatrics \\ Army hospital( R\&R) \\ Delhi, India
}

\author{
Badal Parikh \\ Dept of Anesthesia \\ Army hospital( R\&R) \\ Delhi, India
}

\author{
Pramod Garg \\ Dept of pediatrics \\ Army hospital( R\&R) \\ Delhi, India
}

\section{Abstract}

\section{$>$ Introduction}

Ability to quantify the severity of the patient and predict the probability of death based on the clinical state of admitted child can help decision making selection of treatments, ethical issues and economic strategies .

\section{Aim and objectives}

To analyze clinical and demographic profile of children admitted in PICU and predictive value of PRISM score.

\section{$>$ Material and methods}

It was a prospective, observational, Clinical study. Minimal sample size for the sample to be representative was 240 .Consecutive type of non-probability sampling was used during the study. Receiver operator characteristic curve analysis was done for evaluating the efficacy of PRISM Score to predict mortality.

\section{$>$ Results}

During the study period we had total 315 admissions with 112 being direct admissions while rest 202 were transfer in from ward . out of these 315 patients 262 were either transferred out of PICU or discharged to home while 49 children died thus mortality rate was $15 \%$. At cut-off of 10.5, PRISM score at 12 hours and At cut-off of 8.5, PRISM score at 24 hours had good sensitivity and specificity. An inverse correlation was observed between PRISM score at 12 hours and 24 hours with hospital stay i.e. higher PRISM score was correlating with decreased hospital stay.

\section{$>$ Conclusion}

There was male predominance and younger rage groups among PICU admissions. PRISM score at presentation may be used as a tool in predicting mortality in critically ill children. Hemato-onclogy and postoperative status were the commonest indications for PICU admissions in our set up.

Keywords:- PICU; Clinical profile; PRISM.
Pediatric intensive care units (PICU) are meant to provide sophisticated care for children and adolescents, but increased quantum of therapy can also increase the suffering, financial burden and in the end, may just prolong the death process[1]. Because of this, it is important to be able to quantify the severity of the patient and predict the probability of death based on the clinical state of admitted child[2] This should guide decision making in important issues like selection of treatments, ethical issues and economic strategies[3] .Furthermore, comparing the mortality to the severity of illness, they can be also used to classify patients and may be used to compare clinical studies and technological resources[4].

The Pediatric Risk of Mortality (PRISM) score is one of the main indicators used in the PICU. It was obtained and validated from the Physiologic Stability Index (PSI) [5]. It uses 14 parameters (physiological and laboratory data) and for each one was used the highest severity value recorded in the first 24 hours. The risk of death is calculated by a logistic regression equation using the value of the PRISM, patient age and need of surgery on admission to the PICU[6]. The PRISM has been developed and validated in tertiary PICUs in mostly developed countries[7, 8 ,]with very few reports from India [9-11]. Due to this fact, this study has been planned to evaluate the PRISM score and to correlate it with mortality in patients admitted to the PICU of a northern Indian tertiary referral hospital. We collected data in order to analyze clinical and demographic profile of children admitted in PICU and to see predictive value of PRISM score in our setting for predicting mortality and length of hospital stay.

\section{MATERIAL AND METHODS}

This study was done at PICU of a teaching hospital and tertiary care referral centre of north India. Study Population included all the children who were admitted in PICU between ages 1 month to 18 years of age. It was a prospective, observational, Clinical study conducted from December 2017 to November 2018 with consecutive admitted patients to PICU who were eligible for recruitment in the study. Exclusion Criteria being patients not completing 24 hours in PICU either as they were transferred out or expired. Children whose parents were unwilling to give consent were also no included in the study. After taking informed consent, clinical details and blood samples, relevant for PRISM III (Table 1) 
ISSN No:-2456-2165

\begin{tabular}{|l|c|l|l|}
\hline & Parameter & Within 12 hours & Within 24 hours \\
\hline 01 & Systolic BP & & \\
\hline 02 & Diastolic BP & & \\
\hline 03 & Heart rate & & \\
\hline 04 & Respiratory rate & & \\
\hline 05 & PaO2/FiO 2 & \\
\hline 06 & PaCO2 & & \\
\hline 07 & Glasgow coma score & & \\
\hline 08 & Pupillary reactions & & \\
\hline 09 & PT/PTT & & \\
\hline 10 & Total bilirubin & & \\
\hline 11 & S. Potassium & & \\
\hline 12 & S. Calcium & & \\
\hline 13 & Glucose & & \\
\hline 14 & Bicarbonate in $\mathrm{mEq} / \mathrm{L}$ & & \\
\hline
\end{tabular}

Table 1:- PRISM SCORE components

Calculations were collected at 12 and 24 hours. Minimal sample size for the sample to be representative was 240 calculated based on Danielle's formula with prevalence of PICU admission in our hospital taken as $13 \%$ from data of last 3 years. Consecutive type of non-probability sampling was used during the study. Receiver operator characteristic curve analysis was done for evaluating the efficacy of PRISM Score to predict mortality.

\section{RESULTS}

During the study period we had total 347 admissions out of which 32 were excluded as 9 had died within 12 hours of admission and 23 were shifted out of PICU within 24 hours .Out of 315 admissions with 112 being direct admissions while rest 202 were transfer in from ward .None of the parents denied consent. Outcome of these 315 patients was that 262 were either transferred out of PICU or discharged to home while 49 children died thus mortality rate was $15 \%$. Demographic distribution is shown in table 2.

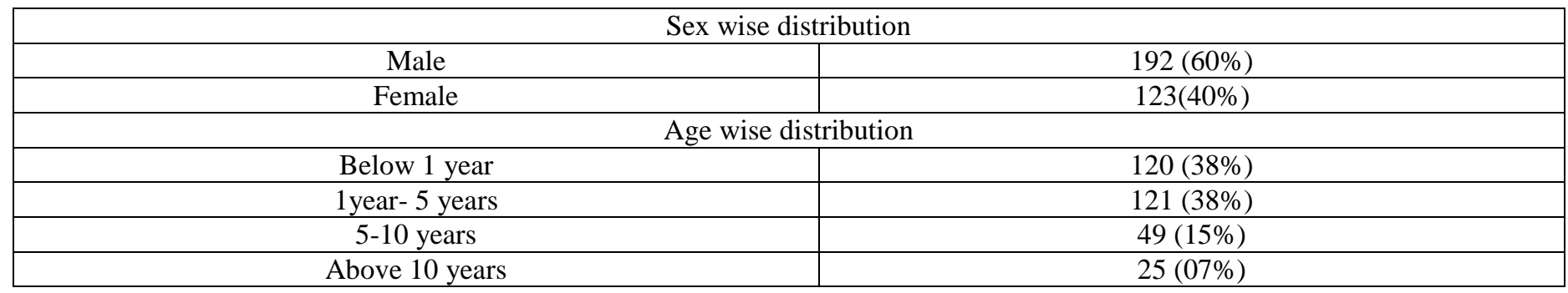

Table 2:- Demographic characteristics among children admitted in PICU during study period

We classified these admissions on basis of primary system involved as shown in table 3 .

\begin{tabular}{|c|c|c|c|}
\hline Primary System & $\begin{array}{c}\text { Total admissions( \% of total } \\
\text { admissions) }\end{array}$ & $\begin{array}{c}\text { Total mortality } \\
\text { admissions in that group) }\end{array}$ \\
\hline Hemato-oncology & $71(22 \%)$ & 17 & $23 \%$ \\
\hline Surgical & $71(22 \%)$ & 3 & $4 \%$ \\
\hline Respiratory & $23(7 \%)$ & 5 & $21 \%$ \\
\hline CNS & $49(15 \%)$ & 4 & $8 \%$ \\
\hline CVS & $23(7 \%)$ & 7 & $6 \%$ \\
\hline Nephrology & $30(9 \%)$ & 2 & $27 \%$ \\
\hline GIT & $18(5 \%)$ & 5 & - \\
\hline Metabolic & $11((3 \%)$ & & $25 \%$ \\
\hline Infection & $12(3 \%)$ & 3 & - \\
\hline Other & $3(1 \%)$ & & \\
\hline
\end{tabular}

Table 3:- Admissions and mortality data based on primary system involvement 
Outcome was also analyzed based on primary diagnosis and revealed that highest mortality was associated with CVS, infection and hemato-oncology. Postoperative cases had low mortality although they were the most common indication for PICU admission .Receiver operator characteristic curve analysis was done for evaluating the efficacy of PRISM Score to predict mortality. Area under ROC curve was 0.875 (CI: 0.813-0.937) and 0.905 (CI: 0.844-0.967) for PRISM score at 12 and 24 hours respectively. At cut-off of 10.5, PRISM score at 12 hours had sensitivity and specificity of $71.8 \%$ and $85.5 \%$ while PPV and NPV was $49.1 \%$ and $94 \%$ respectively. At cut-off of 8.5 , PRISM score at 24 hours had sensitivity and specificity of $86.1 \%$ and $83.8 \%$ while PPV and NPV was $49.2 \%$ and $97.1 \%$ respectively.(Figure 1)

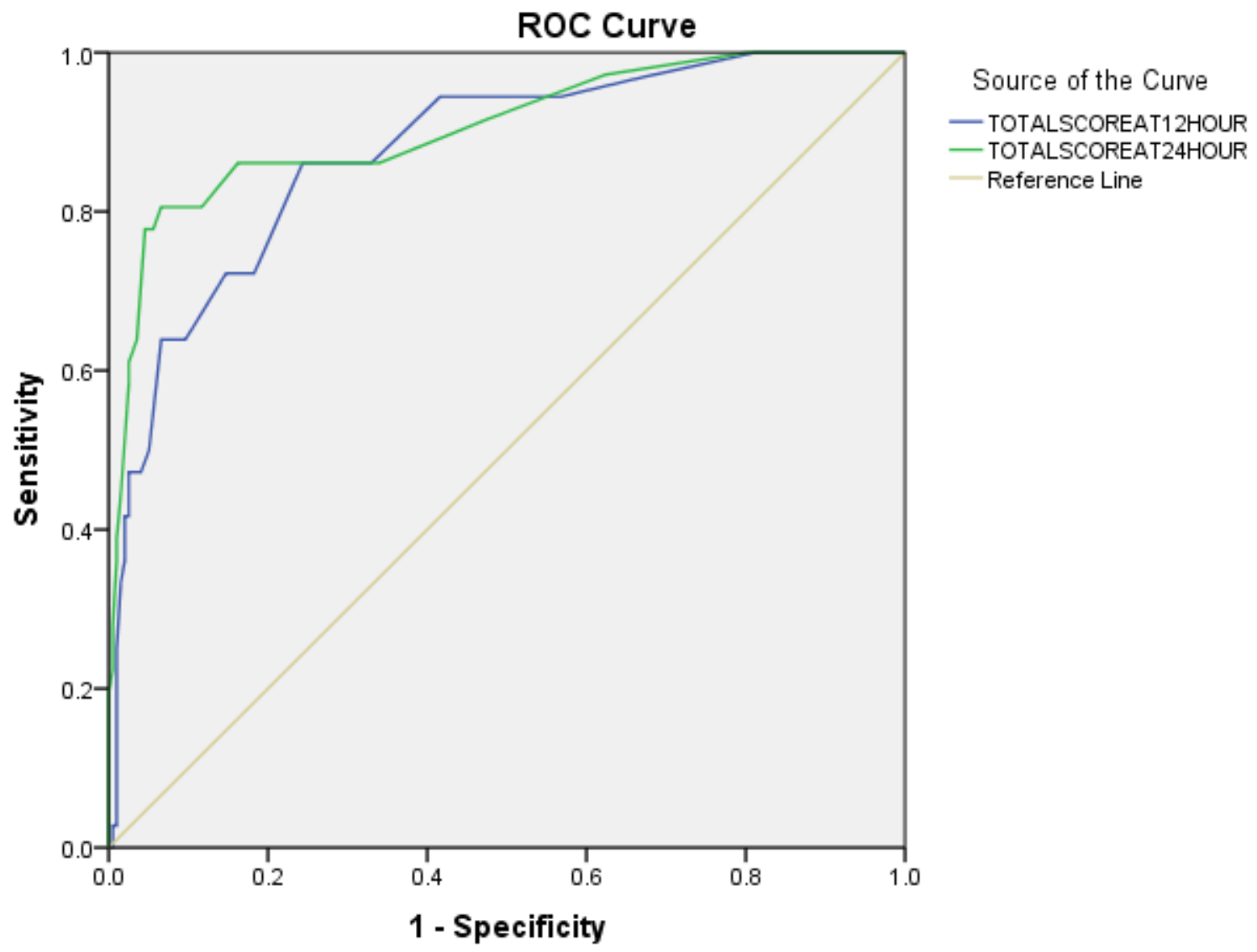

Fig 1:- Receiver operator characteristic curve analysis for PRISM Score to predict mortality

An inverse correlation was observed between PRISM score at 12 hours and 24 hours with hospital stay i.e. higher PRISM score was correlating with decreased hospital stay. The contradictory findings can be attributed to higher mortality (i.e. lower hospital stay) among cases with high PRISM score.(Table 4)

\begin{tabular}{|c|c|c|}
\hline \multicolumn{2}{|c|}{ Pearson co-relation } & p- value \\
\hline PRISM 24 & r-value & $\mathbf{0 . 5 8 5}$ \\
\hline PICU & -0.04 & $\mathbf{0 . 0 4 3}$ \\
\hline Hospital & -0.13 & $\mathbf{0 . 3 9 9}$ \\
\hline PRISM 12 & & -0.06 \\
\hline PICU & -0.17 & $\mathbf{0 . 0 1 1}$ \\
\hline
\end{tabular}

Table 4:- correlation of Prism score with length of hospital stay and PICU stay 


\section{DISCUSSION}

Analysis of demographic distribution shows that in PICU more male children got admitted during study period than female children and this difference was statistically significant. This may reflect male susceptibility to various serious diseases but it could also be because of more likelihood of a male child to be brought to PICU as compared to female child due to still existing preference to a male child among Indian families. This finding is similar to PICU data generated from North India like recently published study by Makhija et al[12]. Age wise distribution emphasizes vulnerability in early age with maximum admissions in first year of life $(38 \%)$ and in age group between 1-5 years (38\%). This finding highlights the importance of infant mortality rate and under five mortality rates as overall indices for health care system of a country. In our experience most common PICU admission indications were related to hemato-oncology and surgical and neurological involved were followed by this and that. This is very different from other studies where infection and respiratory distress are the commonest indications[13]. This reflects the difference in our patient population and it being a referral center where admissions are based on referral and direct admissions are catered at another hospital. This gives a future direction that PICUs specifically catering to hemato-oncolgy and post surgical can be developed in future like pediatric cardiac ICUs which are already functional in our hospital as well as at many institutes in India.

Overall mortality among PICU admission was $15 \%$ which is comparable to other PICUs as reported by Singhal $\mathrm{D}$ et al[14], Madaan et al[15] and Hassan et al[16] with mortality rates of $18 \%, 12.5 \%$ and $17 \%$ respectively. Probability of death based on primary system involved revealed that children with cardiovascular system involvement were most likely to die in PICU. The reason of this is that only children who came to general PICU were the ones where surgery could not be offered either because of poor general condition or secondary to inoperable cardiac condition. Although admission numbers of children requiring surgical management and those having hematooncolgy diseases were similar there was marked difference in mortality with former group having $4 \%$ mortality while later had significantly higher rate of $23 \%$. This reflects impact of basic disease and treatment related complications like febrile neutropenia are more common with hematoncological disorders.

In present study, mean PRISM score at 12 and 24 hours was significantly higher among expired. PRISM 12 score of 10.5 and PRISM 24 score of 8.5 were reasonable cut off points in our study to predict chances of survival and mortality. Our results are also comparable to other studies showing PRISM score as a as a sensitive predictor of mortality[13-17]. El-Nawawy A et al[18] in their study observed that non-survivors had a significantly higher mean score compared with survivors (36 vs. 17). Bellad et al. reported an overall mortality of $16.7 \%$ with $89.2 \%$ accuracy at cut-off score of 15[19]. Costa A et al[20] observed median pediatric risk of mortality score as significantly lower in patients who survived $(p<0.01)$. Singhal D et al[14] in their study, on ROC analysis showed area under the curve of PRISM as 72\%. Madaan et al.[15] in their study too observed PRISM score to be significantly higher among expired cases as compared to survived ones $(7.58 \pm 5.03$ versus $20.63 \pm 3.41 ; \mathrm{p}<0.01)$. Hassan ZE et al.[16] in their study observed that Prism score $>8$ as a significant predictor of mortality (chi-square value of 29.615 and a OR of 9.28 (9 times more risk of dying compared to patients with a prism score $>8$ ). Dey et al[21] in their study observed PRISM as a sensitive predictor of outcome at a cut-off point of 13.5 .

An inverse but non-significant correlation was observed between PRISM score with PICU and hospital stay. This contradictory findings can be attributed to higher mortality among cases with high PRISM score. At cut-off of 15, hospital stay decreased significantly i.e. higher mortality (i.e. lower hospital stay) was associated with PRISM score > 15. Madaan et al[15] did not observe any difference in the mean duration of ICU stay among the survivor and non-survivors. Bellad et $\mathrm{al}^{18}$ reported that the mean ICU stay among non-survivor was shorter when compared to those survivors. As the inverse of the correlation between PRISM and mean ICU stay is considered to be an indicator of the quality of PICU services [22], a difference in the quality of care available at various centers may explain the observed variability in the ICU stay being reported in different studies. Brindha et al[23 ]attributed the median length of PICU stay with the type of primary disease condition affecting the patients and not to the PRISM score of the patients.

\section{CONCLUSION}

The present study was done in a tertiary care referral hospital to evaluate the demography, clinical profile and outcome of patients admitted to PICU by using PRISM score. There was male predominance among PICU admissions and younger rage groups ( infants and below five were disproportionately represented in the PICU population. PRISM score at presentation may be used as a tool in predicting mortality in critically ill children. In our setup hemato-oncolgy and postoperative status were the commonest indications for PICU admissions giving us a roadmap for future development of PICUs specifically catering to this population. 


\section{REFERENCES}

[1]. Batista CC, Gattass CA, Calheiros TP, Moura RB. Avaliac,ão progno'stica individual na UTI: $\mathrm{e}^{\prime}$ possı'vel diferenciar insiste^ncia terape^utica de obstinac, a o terape^utica? Rev Bras Ter Intensiva. 2009;21:247-54,

[2]. Gunning K, Rowan K. ABC of intensive care: outcome data and scoring systems. BMJ. 1999;319:241-4.

[3]. Kalil Filho WJ, Delgado AF, Schvartsman B, Kimura HM. Ana'lise Cli'nica e Progno'stica da Si'ndrome de Disfunc,a ${ }^{\sim o}$ Orga nica Mu'ltipla. Pediatria $\left(\mathrm{Sa}^{\sim} \mathrm{O}\right.$ Paulo). 1995;17:143-7.

[4]. Seneff M, Knaus WA. Predicting patient outcome from intensive care: a guide to APACHE, MPM, SAPS, PRISM, and other prognostic scoring systems. J Intensive Care Med. 1990;5:33-52.

[5]. Pollack MM, Ruttimann E, Getson PR. Pediatric risk of mortality (PRISM) score. Crit Care Med. 1988; 16: 1110-6.

[6]. Yeh TS, Pollack MM, Ruttimann UE, Holbrook PR, Fields AI. Validation of a physiologic stability index for use in critically ill infants and children. Pediatr Res. 1984;18:445-51.

[7]. Shann F, Pearson G, Slater A, Wilkinson K. Paediatric index of mortality (PIM): A mortality prediction model for children in intensive care. Intensive Care Med. 1997;23(2):201-7.

[8]. Pollack MM, Patel KM, Ruttimann UE. The pediatric risk of mortality III--Acute physiology score (PRISM III-APS): A method of assessing physiologic instability for pediatric intensive care unit patients. J Pediatr. 1997;131(4):575-81.

[9]. Singhal D, Kumar N, Puliyel JM, Singh SK, Srinivas V. Prediction of mortality by application of PRISM score in intensive care unit. Indian Pediatr. 2001;38(7):714-7.

[10]. Taori RN, Lahiri KR, Tullu MS. Performance of PRISM (pediatric risk of mortality) score and pim (pediatric index of mortality) score in a tertiary care pediatric ICU. Indian J Pediatr. 2010;77(3):267-71.

[11]. Bellad R, Rao S, Patil VD, Mahantshetti NS. Outcome of intensive care unit patients using pediatric risk of mortality (PRISM) score. Indian Pediatr. 2009;46(12):1091-2.

[12]. Mukhija G, Chandra S, Prasad P.L. Clinical profile of patients admitted to the PICU of a tertiary care teaching hospital. J PediatrRes.2017;4(02):127129.doi:10.17511/ijpr.2017.02.06.

[13]. S M Roy , S Basu , B C Roy , S Datta . Clinical Profile and Outcome of Patients Admitted to Pediatric Intensive Care Unit of a Tertiary Care Teaching Hospital in Eastern India . JMSCR,2018;6(9)1071-5

[14]. Singhal D, Kumar N, Puliyel JM, Singh SK, Srinivas V. Prediction of mortality by application of PRISM score in intensive care unit. Indian pediatrics. 2001 Jul;38(7):714-20.
[15]. Madaan G, Bhardwaj AK, Sharma PD, Dhanjal GS. Validity of pediatric risk of mortality score in prediction of mortality in North Indian pediatric intensive care unit. Indian Journal of Child Health. 2014;1(3):105-8.

[16]. Zul Eidain Hassan, Irfan Quyoom, Iqbal Mushtaq. Validity of PRISM score in predicting mortality in a tertiary care hospital in North India. International Journal of Contemporary Medical Research 2018;5(9):I6-I8.

[17]. Balakrishnan G, Tom Aitchison, David Hallworth, Morton NS. Prospective evaluation of Pediatric Risk of Mortality Score. Arch Dis Child 1992; 67:196-200.

[18]. El-Nawawy A. Evaluation of the outcome of patients admitted to the pediatric intensive care unit in Alexandria using the pediatric risk of mortality (PRISM) score. Journal of tropical pediatrics. 2003 Apr 1;49(2):109-14.

[19]. Bellad RO, Rao S, Patil VD, Mahantshetti NS. Outcome of intensive care unit patients using pediatric risk of mortality (PRISM) score. Indian Pediatr. 2009 Dec 1;46(12):1091-2.

[20]. de Araujo Costa G, Delgado AF, Ferraro A, Okay TS. Application of the Pediatric Risk of Mortality Score (PRISM) score and determination of mortality risk factors in a tertiary pediatric intensive care unit. Clinics. 2010 Nov;65(11):1087.

[21]. Dey PK et al. Prediction of mortality risk by application of Pediatric Risk of Mortality (PRISM) score in tertiary care Pediatric Intensive Care Unit-A prospective observational study. JMSCR. 2019; 7(4):54-61.

[22]. Michel E, Zernikow B. Can PRISM predict length of PICU stay? an analysis of 2000 cases. Med Inform Internet Med. 2003;28(3):209-19.

[23]. Brindha SM, Jayashree M, Singhi S, Taneja N. Study of nosocomial urinary tract infections in a pediatric intensive care unit. J Trop Pediatr. 2011;57(5):357-62. 